\title{
Risk Prediction Analysis of Oil Spill for the Channel of Changxing Island
}

\author{
Lei Liu*, Jianguo Lin and Yuchi Niu \\ College of Environmental Science and Engineering, Dalian Maritime University, Dalian, 116026, China \\ ${ }^{*}$ Corresponding author
}

\begin{abstract}
This paper adopted the model of the particles to predict oil film dynamic drift process. The prediction was supposed to happen in the channel of Changxing Island, and it carried through under four kinds of circumstances. The circumstances are no wind condition, NNE, WSW and SSW. Through simulating the drift process on the oil film motion, the affection after the oil spilling is analyzed, especially the influence to the sensitive targets. Thus, it can provide certain guiding role for the establishment of contingency plans.
\end{abstract}

Keywords-changxing island; oil spilling; model of oil particles; risk

\section{INTRODUCTION}

Petroleum and its products will cause serious pollution in the process of mining, refining, shipping and use, if they are into the marine. And the oil spilling is the most harmful. According to statistics, oil spilled into the ocean for tanker accidents in the world is about 390,000 tons each year. Oil spilled into the ocean in our country is about 120,000 tons every year, and the average mass concentration of oil offshore has reached $0.55 \mathrm{mg} / \mathrm{L}$, and pollution levels are gradually intensified. [1,2] In addition to nutritive salt, petroleum hydrocarbon has become the main pollutants to the ocean (especially in the shallow water) in the world. [3] Different from the conventional pollutants, oil pollution is persistent, cumulative, migratory and highly toxic. Once pollution happens, it will cause serious threat to human health. Thus, predicting the risk of oil spill in time and making reasonable emergency plan play an important role in protecting the ocean.

All the time, domestic and foreign scholars have made

Many important achievements in the study of sea overflow oil prediction model. For instance, Fay $(1969,1971)[4,5]$ proposed the theory of three phase oil film extension in the extension of oil spill simulation. It consists of gravity-inertia, gravity-viscous force and force surface tension-viscosity force balance. On the basis of theory of Fay, Mackay(1980)[6] considered the influence of the wind and established respectively the calculation formula about extension of thick or thin oil film. Díaz, B. et al. [7] used a particle tracking model to examine oil film diffusion after the oil spill of the "prestige". Simulation results demonstrate that this model can accurately provide the environmental impact of time and scope. On the basis of the three stage theory, Liu Xiaokong et al. (1981) [8] put forward the unified formula of expanding scale change over time. Considering the oil film extensions, anisotropic diffusion and loss of the oil film on the edge of the process at same time, Zhao Wenqian et al. (1987, 1992) [9] established the mathematical model of extended range. But on the whole, the model of oil particles becomes more and more popular because it has formed a mature system.

The article will take the channel near Changxing Island for example. According to the actual situation of the nearby sea area agitation, we determine the Changxing Island waterway entrance section as oil spill site of the channel. The different wave combination track prediction of oil spill will be simulated through the establishment of reasonable oil spill model. The result can offer some guidance to establish reasonable oil spill emergency plan.

\section{THE GEOGRAPHICAL POSITION AND THE PRESENT SITUATION OF REGIONAL ENVIRONMENT}

\section{A. The Geographical Position}

Changxing Island $\left(121^{\circ} 16^{\prime} \mathrm{E}, 39^{\circ} 31^{\prime} \mathrm{N}\right)$ is located in the west side of the Liaodong peninsula and the middle of the Bohai sea side of Dalian coastline .It is the largest island in north of the Yangtze river. As an important port located in the Bohai sea of Dalian city, its geographical position is extremely superior.

\section{B. The Regional Natural Environment and Social Environment}

Belonging to marine climate, it is influenced by the monsoon. It's more northerly winds in winter and more southerly winds in summer. An average annual rainfall is $578.3 \mathrm{~mm}$, and the average temperature is $10.0^{\circ} \mathrm{C}$, and the years of average relative humidity is $67.5 \%$.Tidal belongs to irregular semidiurnal tide, and current belongs to regular semidiurnal shallow sea tide.

Since the building in 2005, the economy of Changxing Island development zone is developing rapidly. Marine fishery resources and tourist resources are rich, known as "sea pearl". Nearby coast is the main habitat of wildlife leopard seal under state protection (second grade).

\section{OIL SPILL MODEL}

\section{A. "Oil Particles” Model}

"Oil particle" model [10] is a kind of simulation method that the oil spill is looked as a collection of a large number of particles, and the process of oil spill behavior in the water 
environment is expressed with the macro motion of particles .Horizontal flow of the oil film can be implemented by tracing the trajectory of the particle, and the simulation can use Lagrange method. Diffusion process of particles caused by shear flow and turbulent is random, which can be simulated by the random walk method.

\section{1) Advection Process}

Oil spill is influenced by wind and current. Firstly, center of oil film is in the initial position. Then, it drifts to a new location by one time step $(\Delta \mathrm{t})$, and $\alpha_{\text {is wind factor. }}$ First of all, the sum of the product of the coefficient of the wind and the wind speed and wave speed is integrated in the time $\Delta t$, then, the new location is equal to the sum of the initial position and the integral result.

\section{2) Horizontal Diffusion Process}

The turbulent diffusion process can be simulated by random walking method. Random diffusion distance can be described. Firstly, the six times of the product of diffusion coefficient and $\Delta t$ is obtained, then the result is opened quadratic. Finally, the result multiplies R. And R can be determined by the uniformly distributed random number.

Therefore, the horizontal displacement of a single particle in a time period can be expressed as the sum of three parts. The three parts are the initial position, random diffusion distance and the product of the sum of the product of the coefficient of the wind and the wind speed and wave speed with $\Delta \mathrm{t}$.

\section{OIL SPILL SIMULATION}

In the event of oil spill, numerical model is established to understand reservoir extension speed and extension of drift within a certain time range. Thus, we can take corresponding measure in time to minimize the damage to environment. [11]

\section{A. The Setting of the Oil Spill Situation}

The prediction of oil spill simulation of the Changxing Island selected channel entrance section as the channel of spilled oil spill site: $39^{\circ} 27^{\prime} 54^{\prime \prime} \mathrm{N}, 121^{\circ} 13^{\prime} 00^{\prime \prime} \mathrm{E}$.Oil spill quantity is 100 tons and overflow duration is three hours. The selected four wind directions are no wind condition, NNE, WSW and SSW. Besides, the wind speed of all the above condition is $10 \mathrm{~m} / \mathrm{s}$.

\section{B. Oil Spill Drift Path And Environmental Risk}

Oil film moves because of the common role of wind and current after oil spill. The speed and direction of the wind and ocean current decide the speed and direction of drift.

\section{1) No wind condition}

In no wind condition, the oil spill is influenced by the pure diffusion. Figure 1 gives a few time of drift process after oil spill. It can be seen that the oil film drifts soothly under the action of tide after oil spill. In the initial phase, the oil spilled over a period of time, and the advection gradually formed long and narrow "floating oil zone". The first spilled oil begins arriving out of the south border of the calculated area in the second hour. Since the fifth hour, the flood current started and oil spill under the action of flood current drifts to the north. In the ninth hour, oil spill drifts out from the north. The oil spill drifts to the south under the action of tide after tenth hour. On the whole, the oil spill in the west sea area of Changxing Island makes reciprocating drift in north and south. In this process, part of the oil film may land in the shores of the mouth of the bottle gourd valley. When in the process of the oil film drifting to the north, the oil film may enter the leopard seal core area of nature reserves.

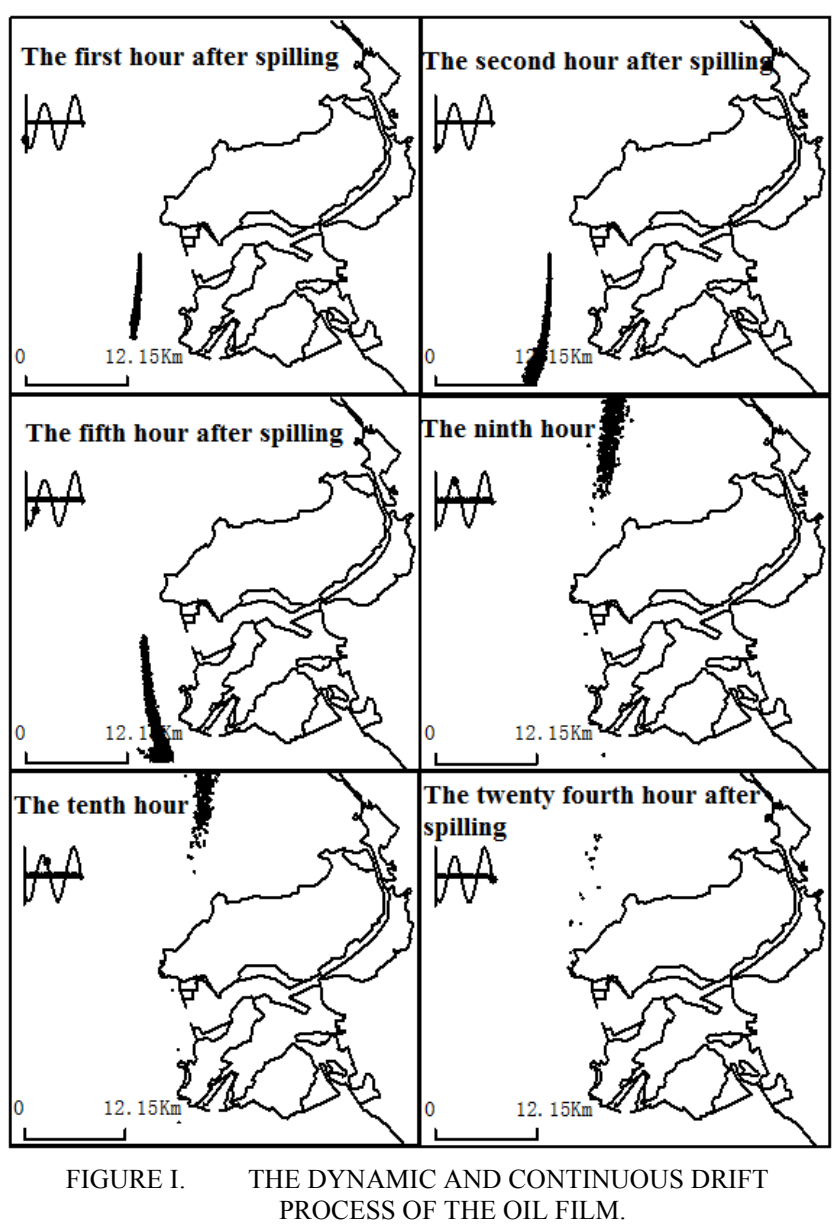

2) $N N E$

The calculation results of oil spill drift and extension because of NNE wind and tide are shown in figure 2 . In this case, the oil spill drifts to the south and the oil film is all out of the area from the south boundary after 5 hours.

\section{3) WSW}

The calculation results of oil spill drift and extension because of WSW wind and tide are shown in figure 3 . In this case, the oil spill drifts to the southeast or the east. Part of the oil film can be landing on the south bank of the gourd 
valley in the second hour. After 4 hours, the other part of the oil film is into the port area of the gourd valley over the entrance. Part of the oil film into port drifts cyclotron in the port area and gradually beaches on the shore.

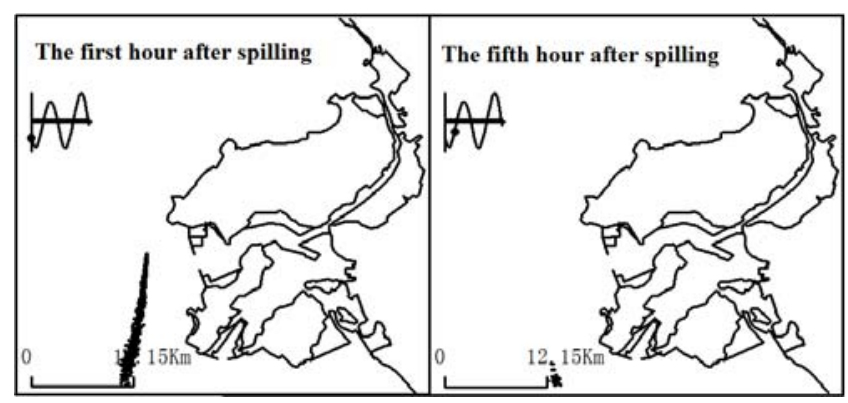

FIGURE II. THE DYNAMIC AND CONTINUOUS DRIFT PROCESS OF THE OIL FILM(NNE AND CURRENT).

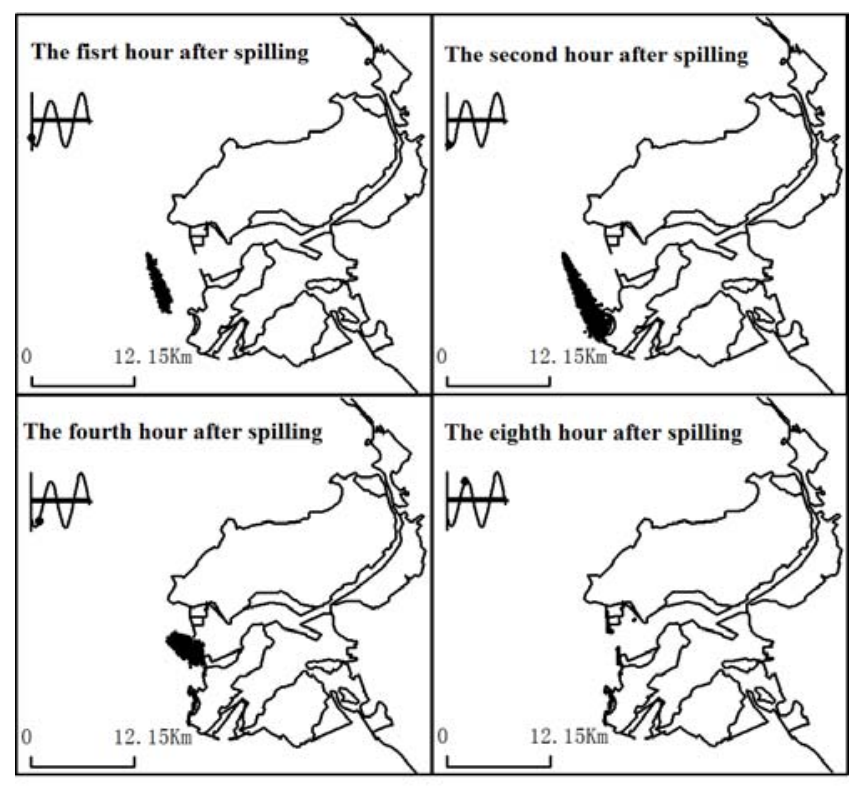

FIGURE III. THE DYNAMIC AND CONTINUOUS DRIFT PROCESS OF THE OIL FILM(WSW AND CURRENT).

\section{4) SSW}

The calculation results of oil spill drift and extension because of SSW wind and tide are shown in figure 4. In this case, oil film driven by ebb current and SSW drifts to the southeast in the initial stage. Then, oil film driven by flood current and SSW drifts to the northeast. In the fourth hour, part of the film arrives at the southwestern shore of Changxing Island, and another part of the oil film drifts to north and is into the leopard seal nature reserve after 5 hours.

\section{Analysis about the Influence of the Environmental Protection Goal}

The numerical simulation of the oil spill accident behavior in general shows that oil film under the action of tide and wind drifts and expands dynamically after oil spill. When there is no wind or breeze sea condition, the western and northwestern sea areas are influenced by oil spill. During the period of flood current, oil spill can be into the core leopard seal nature reserve. Under the NNE wind and tide, oil spill drifts to SBW and affects the ecological environment of the west sea area of Changxing Island. Under SSW wind and tide, oil spill will soon enter the leopard seal core area of nature reserves. In the condition of onshore wind, oil spill would soon land in west coast of Changxing Island.

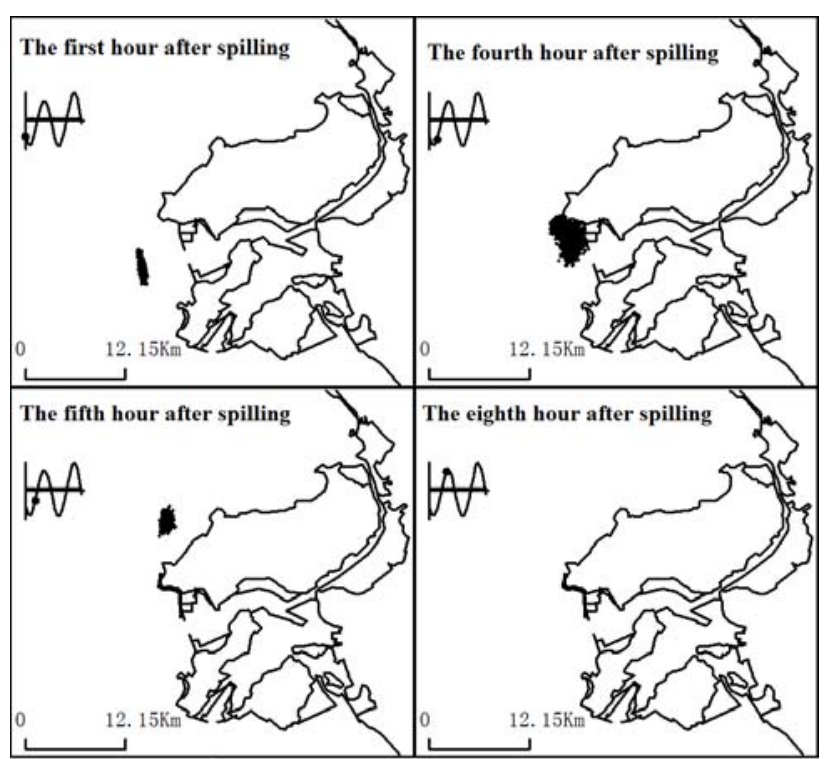

FIGURE IV. THE DYNAMIC AND CONTINUOUS DRIFT PROCESS OF THE OIL FILM(SSW AND CURRENT).

\section{CONCLUSION}

This paper adopted the model of the particles to predict environmental risk caused by oil spill of the channel near Changxing Island. It demonstrates that oil film drift can pollute the ecological environment around the sea and Dalian harbor seal nature reserve in a certain period. If emergency measures can be taken for oil spill in time, the harm to the surrounding environment sensitive target can be reduced. The numerical simulation results in this paper can provide valuable reference for the establishment of contingency plans.

\section{REFERENCES}

[1] Chen Yao. The state of oil pollution of China's coastal waters and the prevention [J].Industrial Safety and Environmental Protection, 2003, 29(11): 20-24.

[2] Guo Zhiping. The prevention and control of oil pollution off Chinese coastal waters [J].Journal of Zhejiang Ocean University (Natural Science), 2004, 23(3): 269-272.

[3] Zhao Yunying, Yang Qingxiao. Weathering processes of spilled oil in the marine environment [J].Marine Environmental Science, 1997, 16(1): 45-52

[4] Fay J A. Physical processes in the spread of oil on water surface[R].Proceeding of Conference on the prevention and control of oil spills, American Petroleum Institute, Washington.D.C,1971:463467. 
[5] Fay J A. Oil on the Sea .Plenum: Plenum Press 1969.

[6] D. Mackay, S. Paterson, et al. Calculation of the evaporation Rate of Volatile Liquids[R]. National Conference on Control of Hazardous Material Spill, Louisville, 1980.

[7] Díaz B, et al. Use of a probabilistic particle tracking model to simulate the Prestige oil spill[J]. Journal of Marine Systems, 2008, 7(1-4): 159-166.

[8] Liu S L, Leendertes J J. A 3-D oil spill model with and without ice cover[C]. Proc of the Internet Symposium on Mechanics of oil slicks. Paris, France: 1981.

[9] Wu Zhouhu, Zhao Wenqian. The surface of the extension, discrete and migration of the oil spill [J]. Marine Environmental Science, 1992,11(3):33-40.

[10] Liu Qinzheng, Zhang Cunzhi, Liu Yu, et al. On the oil-spill forecast system in the BoHai sea[J]. Marine Forecasts, 2005, 22: 70-73

[11] Peng Lin, Pan Nanming, Sun Qun. Environmental impact assessment of oil spill and the example analysis[J]. Environment, 2008, S1:61-62 